\title{
LA NECESIDAD DE INCORPORAR EL HIDRÓGENO COMO POTENCIAL FUENTE ALTERNA DE ENERGÍA EN LA LEGISLACIÓN MEXICANA
}

\author{
José JuAn Alvarado FLORES \\ Doctor en Ciencia de Materiales \\ Profesor investigador
}

Facultad de Ingeniería Química, Universidad Michoacana de San Nicolás de Hidalgo cedhryck@hotmail.com

JAIME ESPINO VALENCIA

Doctor en Ciencia de Materiales

Profesor investigador

Facultad de Ingeniería Química, Universidad Michoacana de San Nicolás de Hidalgo jespinova@yahoo.com.mx

MARÍA LILIANA Ávalos RODRÍGUEZ
Maestra en Derecho y Gestión Ambiental

Instituto de Investigaciones Económicas y Empresariales, Universidad Michoacana de San Nicolás de Hidalgo

lic.ambientalista@gmail.com

Recibido: 20 de marzo de 2015 / Aceptado: 15 de abril de 2015 
RESUMEN: La energía es uno de los motores más importantes que mueven a las sociedades. El desarrollo de un sistema energético a base de hidrógeno $\left(\mathrm{H}_{2}\right)$ está respaldado por dos grandes fuerzas, la seguridad energética y la problemática medioambiental. Considerando la celda de combustible (SOFC) como el principal receptor del $\mathrm{H}_{2}$, se obtendría el potencial de crear un sistema energético eficiente, limpio y sostenible en las próximas décadas. El factor más importante a mejorar a corto plazo es el desarrollo de mejores sistemas de almacenamiento del $\mathrm{H}_{2}$. En México, el marco institucional para la promoción y aplicación de energías alternas es muy limitado, puesto que se prefiere desarrollar tecnologías para el aprovechamiento de fuentes tradicionales de energía; hay desconocimiento por parte de las autoridades de la magnitud y el posible aprovechamiento del $\mathrm{H}_{2}$ como fuente alterna de energía. La normativa mexicana no hace referencia al $\mathrm{H}_{2}$ como alternativa energética. Por ello, considerando todos los beneficios ambientales, económicos y sociales que se promueven con su uso y aplicación, es pertinente que se incorpore en el marco jurídico mexicano a fin de fomentar la investigación, promoción y aplicación de este elemento como fuente alterna de energía.

RESUM: L'energia és un dels motors més importants que mouen les societats. El desenvolupament d'un sistema energètic a base d'hidrògen $\left(\mathrm{H}_{2}\right)$ rep el suport de dues grans forces, la seguretat energètic i la problemàtica ambiental. Considerant la cel $\cdot$ la de combustible (SOFC) com el principal recepto d' $\mathrm{H}_{2}$, s'obtindria el potencial per crear un sistema energètic eficient, net i sostenible per a les pròximes dècades. El factor més important a millorar, en el curt termini, és el desenvolupament de millors sistemes d'emmagatzemament d' $\mathrm{H}_{2}$. A Mèxic, el marc institucional per a la promoció i l'aplicació d'energies alternatives és molt limitat, ja que es prefereix el desenvolupament de tecnologies per a l'aprofitament de les fonts tradicionals d'energia; hi ha desconeixement per part de les autoritats de la magnitud i el possible aprofitament d' $\mathrm{H}_{2}$ com a font alternativa d'energia. La normativa mexicana no en fa referència. Per això, considerant tots els beneficis ambientals, econòmics i socials que es promouen amb el seu ús i aplicació, és pertinent que s'incorpori en el marc jurídic mexicà, amb la finalitat de fomentar la investigació, la promoció i l'aplicació d'aquest element com a font alternativa d'energia. 
ABSTRACT: Energy is one of the most important engines that move societies. The development of an energy system based on hydrogen $\left(\mathrm{H}_{2}\right)$, is backed by two great forces, energy security and environmental issues. Considering the fuel cell (SOFC) as the main recipient of $\mathrm{H}_{2}$, the potential to create an efficient, clean and sustainable energy system for decades to be obtained. The most important thing to improve shortterm factor is the development of better storage of $\mathrm{H}_{2}$. In México, the institutional framework for the promotion and implementation of alternative energy is very limited; is preferred to develop technologies for the use of traditional energy sources; There is ignorance on the part of the authorities on the extent and possible use of $\mathrm{H}_{2}$ as an alternative source of energy. Mexican law does not refer to $\mathrm{H}_{2}$ as an energy alternative and considering all environmental, economic and social benefits to promote their use and application, it is appropriate to be incorporated in the Mexican legal framework to promote research, promotion and application of this element as an alternative source of energy.

PALABRAS CLAVE: Energías alternativas — Hidrógeno — Legislación mexicana — Celda de combustible (SOFC).

PARAULES CLAU: Energies alternatives — Hidrògen — Legislació mexicanacel·la de combustible (SOFC).

KEY WORDS: Alternative energy — Hydrogen — Mexican law — Fuel cell (SOFC).

SUMARIO: I. Introducción. II. Panorama energético mundial. 1. Demanda energética mundial. 2. Respuesta internacional a la problemática medioambiental. III. Marco normativo de las fuentes alternas de energía en México.1. Bases constitucionales de las fuentes alternas de energía. 2. La Ley para el Aprovechamiento Sustentable de la Energía y el Financiamiento de la Transición Energética (LASEFTE). 3. Reglamento de la Ley para el Aprovechamiento de Energías Renovables y el Financiamiento de la Transición Energética. 4. Ley de Promoción y Desarrollo de los Bioenergéticos. 5. Ley de la Industria Eléctrica. IV. El hidrógeno como fuente alterna de energía. 1. Seguridad del hidrógeno. 2. Riesgos y recomendaciones en las instalaciones de hidrógeno. 3. Propiedades del hidrógeno que lo hacen más seguro que otros combustibles. 4. Medidas básicas en la seguridad del hidrógeno. 5. Selección de materiales en la seguridad del hidrógeno. 6. Almacenamiento del hidrógeno. V. La necesidad de legislar el hidrógeno en México. VI. Discusión y conclusiones. VII. Referencias. 


\section{INTRODUCCIÓN}

Las fuentes de energía renovables, que se encuentran distribuidas con mayor o menor abundancia por todo el planeta, tienen como característica intrínseca el hecho de ser temporales y no almacenables. El hidrógeno $\left(\mathrm{H}_{2}\right)$ es el elemento más abundante del universo, suponiendo el $90 \%$ de la masa total del universo. Además, se encuentra homogéneamente repartido en la Tierra. Tiene propiedades químicas que lo hacen especialmente apto para su uso como combustible; por ejemplo, tiene un poder energético por unidad de masa casi tres veces superior a la gasolina ${ }^{1}$, siendo además factible su almacenamiento, transporte y distribución, lo que permitiría su aplicación a cualquier segmento de la demanda. El hidrógeno presentaría así un gran potencial como un vector energético de las energías renovables. Actualmente, el $\mathrm{H}_{2}$ está introducido en las agendas políticas de países de todo el mundo. Los Estados Unidos, Japón, la Unión Europea y decenas de otros países como Canadá, China, Corea y Australia han lanzado o reforzado acciones, por medio de desarrollos industriales, inversiones y políticas de Estado, en pro del hidrógeno. Las celdas de combustible, que son básicamente sistemas termodinámicos abiertos, serán el medio operativo del $\mathrm{H}_{2}$. Estos dispositivos operan sobre la base de reacciones electroquímicas presentes y de los reactivos consumidos de una fuente externa ${ }^{2}$. En la década de 1980 su uso (celdas) había estado limitado a la industria espacial (NASA) ${ }^{3}$. Hoy en día se está trabajando en la elaboración de normas (ISO/TC197) orientadas a establecer códigos y estándares de seguridad para el uso del $\mathrm{H}_{2}$. La relación hidrógeno-celdas de combustible viene a completar el atractivo que ofrecen las fuentes renovables de energía (incluyendo la bioenergía) en relación con la sustentabilidad y el respeto al medio ambiente. Muchos científicos presentan pleno optimismo en que las celdas de combustible podrán prever la alta demanda energética de los próximos años y disminuir grandemente los problemas de contaminación asociados a las fuentes de energía actuales ${ }^{4}$. México, por su parte, tiene grandes retos

\footnotetext{
${ }^{1}$ RAMSAY, C., "International Partnership for a Hydrogen Economy”, International Energy Agency, 2003.

2 ALVARADO FLORES, J., "Estudio comparativo de las diferentes tecnologías de celdas de combustible", Boletín de la Sociedad Española de Cerámica y Vidrio, núm. 52, 2013, pp. 105-117. http://dx.doi.org/10.3989/cyv.142013.

${ }^{3}$ Hydrogen fuel cells and infrastructure technologies program, U. S. Department of Energy Hydrogen Program, 1980.

4 HIBINO, T., "High performance anodes for SOFCs operating in methane-air mixture at reduced temperatures", Journal of The Electrochemical Society, núm. 149, 2002, pp. A133-A136.
} 
que superar para hacer posible la incorporación del $\mathrm{H}_{2}$ como una fuente alterna de energía; entre ellos, destacan los costos elevados de producción, la baja demanda, la eficacia de las tecnologías de producción del $\mathrm{H}_{2}$, la ausencia de confianza en inversionistas públicos o privados, la falta de políticas públicas que permitan el desarrollo del $\mathrm{H}_{2}$ para generar energías de alcance tecnológico de mercado, la ausencia de apoyos gubernamentales dirigidos a la incorporación del $\mathrm{H}_{2}$ y la participación de los actores de la cadena industrial para incrementar la calidad de los mecanismos de producción y reducir los costos de la extracción del $\mathrm{H}_{2}$.

Como se observa, parte fundamental es reconocer a través del derecho positivo la existencia de responsabilidades en la incorporación del $\mathrm{H}_{2}$ como fuente alterna de energía. Si esta última es reconocida dentro del marco jurídico vigente, los sectores involucrados (gubernamental, privado y social) se verán ante la necesidad de adoptar medidas que incorporen el $\mathrm{H}_{2}$ como una verdadera alternativa, lo que hará eficiente la tecnología mediante la innovación de los procesos. Recientemente, México formó parte de uno de los instrumentos internacionales más importantes para promover y acrecentar el uso de fuentes renovables de energía, para combatir el cambio climático y para fomentar un desarrollo sostenible y sustentable: la Conferencia de las Naciones Unidas sobre el Desarrollo Sostenible, más conocida como Río+20.

El entorno internacional indica que las energías renovables son un tema prioritario en las agendas energéticas, tanto en los países industrializados como en las economías en desarrollo, por sus efectos positivos en las esferas ambiental, económica y social. En este contexto, el Gobierno mexicano llevó a cabo el primer acercamiento para impulsar las energías renovables por parte del Estado con la aprobación de la Ley para el Aprovechamiento de Energías Renovables y el Financiamiento de la Transición Energética. Sin embargo, aun con la aprobación de esta ley, los programas y proyectos de energías renovables implementados en nuestro país son de bajo perfil porque solo buscan promover la producción de energías renovables en áreas como la eficiencia energética en el alumbrado público, la iluminación doméstica, los aparatos electrodomésticos y los automotores. México cuenta con algunos indicios de regulación energética; sin embargo, no profundiza en la incorporación del $\mathrm{H}_{2}$ como alternativa pese a la relevancia científica y tecnológica que representa como fuente alterna de energía. La legislación es relativamente nueva y existen leyes que inciden en el aprovechamiento de la energía a fin de hacer más eficientes los procesos, reducir contaminantes y promover políticas 
públicas en beneficio del aprovechamiento energético ${ }^{5}$. Sin embargo, las normativas vigentes en México no hacen referencia en ninguno de sus apartados al hidrógeno como alternativa energética pese a todos los beneficios ambientales, económicos y sociales que se promueven con su uso y aplicación, por lo que es pertinente que se incorpore en el marco jurídico mexicano a fin de fomentar la investigación, promoción y aplicación de este elemento como fuente alterna de energía.

\section{PANORAMA ENERGÉTICO MUNDIAL}

La energía juega un papel vital en la sociedad moderna. La energía posibilita el funcionamiento de los sistemas que cubren necesidades humanas como la alimentación, el cobijo, el trabajo o el transporte. La fuerte dependencia de las naciones respecto a los combustibles fósiles, en particular el petróleo, comporta una gran preocupación en materia de seguridad energética. La energía es vital en las economías industrializadas, pero igualmente en la generación de avances económicos y sociales en las zonas en vías de desarrollo. Diversos informes realizados por organismos tan relevantes como la Agencia Internacional de la Energía, la Comisión Europea o el Departamento de Energía de los Estados Unidos confirman que las necesidades energéticas a escala mundial continúan aumentando de forma inexorable, así como la dependencia creciente de los combustibles fósiles. Avisan sobre la necesidad de que los gobiernos modifiquen sus políticas energéticas para frenar, por ejemplo, las emisiones de $\mathrm{CO}_{2}$. Se hace en todos ellos una llamada de atención a la evolución de los países en vías de desarrollo, especialmente de Asia, en cuanto a su demanda de energía. La Agencia Internacional de la Energía (IEA, International Energy Agency) asegura, en su informe sobre las

\footnotetext{
${ }^{5}$ Ley para el Aprovechamiento Sustentable de la Energía y el Financiamiento de la Transición Energética y su Reglamento; Ley de Promoción y Desarrollo de los Bioenergéticos; Ley de la Industria Eléctrica; Ley de la Comisión Regulatoria de Energía; Ley General para la Prevención y Gestión Integral de los Residuos; Ley General de Desarrollo Forestal Sustentable; Ley de Petróleos Mexicanos; Ley de Energía Geotérmica; Ley de Energía para el Campo; Ley del Fondo Mexicano del Petróleo; Ley de Impuestos sobre la Renta (artículo 40, fracción XII); Ley que declara reservas mineras nacionales los yacimientos de uranio, torio y las demás substancias de las cuales se obtengan isótopos hendibles que puedan producir energía nuclear; Ley General del Equilibrio Ecológico y la Protección al Ambiente (evaluación del impacto ambiental); Ley de Aguas Nacionales; Ley Orgánica de la Administración Pública Federal (artículo 33); Reglamento de la Ley para el Aprovechamiento Sustentable de la Energía y el Financiamiento de la Transición Energética; Reglamento de la Ley General del Equilibrio Ecológico y la Protección al Ambiente en materia de impacto ambiental; Reglamento de la Ley de Aguas Nacionales; Norma Mexicana NMX-ES-001-NORMEX-2005 de energía solar-rendimiento térmico y funcionalidad de colectores solares para calentamiento de agua, métodos de prueba y etiquetado; Norma Ambiental para el Distrito Federal NADF-008-AMBT-2005, que establece las especificaciones técnicas para el aprovechamiento de la energía solar en el calentamiento de agua en albercas, fosas de clavados, regaderas, lavamanos, usos de cocina, lavandería y tintorería; y Norma Oficial Mexicana PROY-NMX-ES-002-NORMEX-2006.
} 
perspectivas energéticas mundiales ${ }^{6}$, que los recursos energéticos de la Tierra son suficientes para cubrir la demanda de las próximas tres décadas. Sin embargo, esto no garantiza el abastecimiento generalizado. Más aún teniendo en cuenta la concentración de las reservas de los combustibles fósiles en un número cada vez más reducido de países.

\section{Demanda energética mundial}

De la demanda energética mundial se puede decir que sigue aumentando a todos los niveles. Históricamente, la incorporación de nuevas energías primarias no ha supuesto, en general, la disminución en el consumo de las anteriores, que, aunque redujeron sus porcentajes de consumo global, no así sus volúmenes absolutos. Entre los años 1971 y 2001, el consumo de energía a escala mundial aumentó de unos 5.500 millones de toneladas (Mtoe) a más de 10.000 Mtoe, lo que supuso un aumento de en torno al ochenta por ciento en treinta años. En este tiempo la energía consumida por el mundo fue principalmente de origen fósil. La energía procedente del petróleo, carbón y gas natural y la nuclear constituyeron en el año 2001 el 86,5\% del total. Siendo el petróleo la fuente mayoritaria, con más de doce puntos sobre la siguiente. El 13,5\% restante fue aportado por las energías renovables. Siendo en este caso la biomasa, y, por lo tanto, una fuente renovable que emite dióxido de carbono en su combustión, la fuente principal, con un 10,8\%. El conjunto de energía solar, eólica y geotérmica únicamente aportaron el $0,54 \%$ del total. Las previsiones no son mucho mejores: los resultados arrojados por el World Energy, Technology and Climate Outlook (WETO) realizado por la Comisión Europea prevén que el aumento del consumo energético mundial será de un $70 \%$ en el período del 2000 al 2030 . Lo que significa una tasa de crecimiento del $1,8 \%$ al año. Los combustibles fósiles seguirían siendo las fuentes de energía principales, cubriendo el carbón, el petróleo y el gas natural el $88 \%$ de la demanda en el año 2030. Las previsiones que contiene el World Energy Outlook 2004, publicado por la Agencia Internacional de la Energía a finales de octubre de 2004, son parecidas, aunque las cifras varían levemente. El informe prevé que la demanda energética

\footnotetext{
${ }^{6}$ WORLD ENERGY OUTLOOK, International Energy Agency and the organisation for economic cooperation and development, 2004. Recuperado en abril del 2015, de http://www.worldenergyoutlook.org/media/weowebsite/2008-1994/weo2004.pdf.
} 
primaria crezca en una tasa del $1,7 \%$ al año entre 2000 y 2030. Este crecimiento, a pesar de suponer que se alcance un nivel anual de 15.300 Mtoe, o lo que es lo mismo, un aumento de dos tercios en la demanda actual, es menor que el de las pasadas tres décadas, donde se alcanzó el 2,1\% al año.

Hoy en día existen factores determinantes de la demanda energética. Los principales conductores del desarrollo en el futuro de los sistemas energéticos mundiales, según la Comisión Europea, seguirán siendo la demografía y el crecimiento económico (GDP, Gross Domestic Product) ${ }^{7}$. Tanto la evolución de estos dos factores como el punto de partida serán diferentes en cada localización geográfica. En la Unión Europea se espera que la población se mantenga constante durante el período 2000-2030. Además, el aumento del $0,4 \%$ al año en el consumo de energía se debe fundamentalmente al impacto del crecimiento del PIB per cápita $(1,9 \%$ al año). En términos de los porcentajes de los combustibles, la contribución del gas natural crece fuertemente del 2000 al 2030 a expensas del carbón, el petróleo y el gas natural. A finales del período, el gas natural representa el $27 \%$ de la energía total consumida en la UE y se convierte en el segundo combustible más usado detrás del petróleo (39\%), pero por delante del carbón y el lignito (carbón mineral de color negro o pardo en el cual aún se distingue la textura de la madera de que procede). En América Latina la demanda de energía crece a una tasa del 2,4\% al año de media entre 2000 y 2030. Se considera una ligera disminución del petróleo, que es compensada con una fuerte penetración del gas, un recurso abundante en la región.

\section{Respuesta internacional a la problemática medioambiental}

Prácticamente la totalidad de la comunidad científica está convencida de que el aumento de las concentraciones de gases de efecto invernadero va a incrementar la temperatura del planeta, con graves consecuencias para la estabilidad y el equilibrio del clima ${ }^{8}$. A diferencia de la disminución de la capa de ozono, no hay consenso internacional en la

\footnotetext{
7 WORLD ENERGY, TECHNOLOGY AND CLIMATE OUTLOOK 2030 (WETO), European Commission, 2003. Recuperado de http://ec.europa.eu/research/energy/pdf/weto_final_report.pdf.

8 JABBOUR, J., FATOUMATA, K., HUNSBERGER, C., SÁNCHEZ RODRÍGUEZ, R., GILRUTH, PETER., PATEL, N., SINGH, A., A. LEVY, M. y SCHWARZER, S., "Internationally agreed environmental goals: A critical evaluation of progress", Environmental Development, núm. 3, 2012, pp. 5-24. Recuperado de http://dx.doi.org/10.1016/j.envdev.2012.05.002.
} 
lucha contra el cambio climático ${ }^{9}$ y las acciones emprendidas llegan tarde pues el cambio climático ya es una realidad. Todo ello ha llevado al cuestionamiento de la eficacia y el efectivo cumplimiento del Protocolo de Kioto ${ }^{10}$.

El Protocolo de Kioto, actualmente vigente del 1 de enero de 2012 hasta el 31 de diciembre de 2020, es un acuerdo internacional que se deriva de la Convención Marco de las Naciones Unidas sobre el Cambio Climático. Fue negociado en 1997 y se promovió que 37 países desarrollados redujeran sus emisiones de gases de efecto invernadero (GEI). Este acuerdo detalla cómo alcanzar esa meta grupal a través de objetivos legalmente vinculantes que cada país desarrollado decide a nivel doméstico. Los logros de este acuerdo han sido muy limitados debido a que Estados Unidos, principal productor de GEI, no lo ratificó y, por lo tanto, tampoco lo acató ${ }^{11}$. Como país en desarrollo, México no tiene ninguna obligación de reducción de emisiones bajo el Protocolo de Kioto. No obstante, dado que las emisiones nacionales se incrementan año tras año, Greenpeace consideró que México, así como otros países en desarrollo, debían asumir compromisos obligatorios de reducción para después de 2012 y antes de $2020^{12}$.

\section{MARCO NORMATIVO DE LAS FUENTES ALTERNAS DE ENERGÍA EN MÉXICO}

Es bien sabido que las tecnologías del hidrógeno $\left(\mathrm{H}_{2}\right)$ se han convertido en una necesidad que motiva a disponer de métodos apropiados para su almacenamiento y utilización, garantizando la demanda y el balance energético. Esta problemática ha impulsado al hombre a buscar en las alternativas energéticas renovables —obtenidas de forma directa o derivadas del sol, el viento, la hidroenergía, la geotermia o la biomasa-

\footnotetext{
9 VASILEIADOU, E., HEIMERIKS, G. y PETERSEN, A., "Exploring the impact of the IPCC Assessment Reports on science", Environmental Science \& Policy, núm. 14, 2011, pp. 1052-1061. Recuperado de http://dx.doi.org/10.1016/j.envsci.2011.07.002.

${ }^{10}$ SHAIKH, M. y KIRKMAN, G., "Costs of certified emission reductions under the Clean Development Mechanism of the Kyoto Protocol”, Energy Economics, núm. 47, 2015, pp. 129-141. Recuperado de http://dx.doi.org/10.1016/j.eneco.2014.10.020.

${ }^{11}$ DAGOUMAS, A., PAPAGIANNIS, G. y DOKOPOULOS, P., "An economic assessment of the Kyoto Protocol application”, Energy Policy, núm. 34, 2006, pp. 26-39. Recuperado de http://dx.doi.org/10.1016/j.enpol.2004.05.012.

12 GREENPEACE MÉXICO, "El protocolo de Kioto". Recuperado en mayo de 2015, de http://www.greenpeace.org/mexico/es/Campanas/Energia-y--cambio climatico/COP16/Antecedentes/Protocolo-de-Kioto/
} 
el recurso energético primario que le permita mantener el consumo per cápita, sumándose a ello que un tercio de la población mundial todavía carece de servicios energéticos ${ }^{13}$. La Red Nacional del Hidrógeno ha considerado que, por la necesidad de energía, el futuro será llamado "la economía del hidrógeno", que remplazará la economía de los combustibles fósiles; por ello, países con un alto grado de industrialización están llevando a cabo acciones que tienden a incentivar el $\mathrm{H}_{2}$ en los procesos, creando e innovando en su tecnología a fin de hacer posible esta realidad. México ha propiciado la incorporación de las fuentes alternas de energía en el marco jurídico, haciendo énfasis en las fuentes de energía renovable, que, a pesar de su relevancia e importancia, a futuro no ofrecen una alternativa como tal en energía, de ahí la importancia de impulsar las investigaciones que incorporan elementos como el $\mathrm{H}_{2}$ y hacen posible esa realidad alternativa; pero para ello es necesario un respaldo jurídico que asiente las bases para delimitar las conductas en la sociedad, estableciendo responsabilidades en el uso y manejo del $\mathrm{H}_{2}$ como fuente alternativa, los alcances y las limitaciones en su aplicación y la regulación de sus beneficios.

Recientemente México formó parte de uno de los instrumentos internacionales más importantes para promover e incrementar el uso de fuentes renovables de energía para combatir el cambio climático y fomentar un desarrollo sostenible y sustentable: la Conferencia de las Naciones Unidas sobre el Desarrollo Sostenible, más conocida como Río+20. El entorno internacional indica que las energías alternativas son un tema prioritario en las agendas energéticas tanto en los países industrializados como en las economías en desarrollo debido a sus efectos positivos en las esferas ambiental, económica y social.

En este contexto, el Gobierno mexicano dio el primer acercamiento para impulsar las energías renovables por parte del Estado con la aprobación de la Ley para el Aprovechamiento de Energías Renovables y el Financiamiento de la Transición Energética. Sin embargo, aun con la aprobación de esta ley, los programas y proyectos que operan sobre energías renovables que se han implementado en nuestro país son de bajo perfil porque solo promueven la producción de energías renovables en áreas de producción como la eficiencia energética en el alumbrado público, la iluminación en

\footnotetext{
13 RED NACIONAL DEL HIDRÓGENO, S.A. de México, Historia de las aplicaciones del $\mathrm{H}_{2}, 2015$. Recuperado en abril de 2015, de http://www.rnh2.org/4.html.
} 
casa, los aparatos electrodomésticos o los automotores. A raíz de la formalización de compromisos internacionales, México ha colocado el aprovechamiento de las energías renovables como un elemento fundamental de las políticas públicas dentro de los planes nacionales de desarrollo y la sustentabilidad ambiental como uno de sus ejes. Así, el marco jurídico mexicano en materia energética está comprendido por la Constitución Política de los Estados Unidos Mexicanos (CPEUM), los tratados internacionales, la Ley General del Equilibrio Ecológico y la Protección al Ambiente (LGEEPA), las leyes federales sectoriales aplicables en materia ambiental, los reglamentos de la Ley General Ambiental y de las leyes sectoriales, las normas oficiales mexicanas ambientales, los acuerdos administrativos, los acuerdos o convenios de coordinación o concertación y las políticas públicas. Por ello, conviene puntualizar, analizar y relacionar su contenido para cumplir el objetivo del presente escrito.

\section{Bases constitucionales de las fuentes alternas de energía}

En la Constitución Política de los Estados Unidos Mexicanos no se hace referencia expresa a las energías renovables ${ }^{14}$. Sin embrago, existen tres preceptos vinculados directa o indirectamente con dichas formas de energía: el primero es el derecho que toda persona tiene a un medio ambiente sano para su desarrollo y bienestar; el segundo refiere la atribución que corresponde al Estado en la rectoría del desarrollo nacional, para garantizar que este sea integral y sustentable, entendiendo esto último como el uso óptimo de los recursos; y el tercero es el derecho de la Nación de regular, en beneficio social, el aprovechamiento de los elementos naturales susceptibles de apropiación, con objeto de hacer una distribución equitativa de la riqueza pública, cuidar de su conservación y lograr el desarrollo equilibrado del país y el mejoramiento de las condiciones de vida de la población rural y urbana ${ }^{15}$. Puntualizando, el artículo 25 constitucional señala que corresponde al Estado planear, conducir, coordinar y orientar el desarrollo económico nacional y llevar a cabo la regulación y el fomento de las actividades que demande el interés general, con la participación de los sectores social y privado. También señala que, bajo criterios de equidad social y productividad, se

\footnotetext{
${ }^{14}$ Únicamente el artículo decimocuarto transitorio del Decreto de Reforma en Materia Energética se refiere a las energías renovables en cuanto a alguna posible participación del Fondo Mexicano del Petróleo para la Estabilización y el Desarrollo.

${ }^{15}$ Constitución Política de los Estados Unidos Mexicanos, artículos 4, 25 y 27, respectivamente.
} 
apoyará e impulsará a las empresas de los sectores social y privado de la economía, sujetándolos a las modalidades que dicte el interés público y al uso, en beneficio general, de los recursos productivos, cuidando su conservación y el medio ambiente. Por lo tanto, es una atribución del Estado proveer a los sectores social y productivo de los parámetros que promuevan y garanticen el uso de energías renovables como una transición energética. Más aún si se considera que la diversificación de las energías promueve la seguridad energética y posibilita un desarrollo sostenible. El artículo 27 constitucional es relevante porque refiere que solo la Nación debe generar, conducir, transformar, distribuir y abastecer energía eléctrica que tenga por objeto la prestación de servicio público. En esta materia no se otorgarán concesiones a los particulares y la Nación aprovechará los bienes y recursos naturales que se requieran para dichos fines. En efecto, se le confiere al Estado el derecho de hacer uso de sus bienes y recursos naturales para producir energía eléctrica.

El Estado mexicano está en pleno uso de sus facultades al utilizar el viento, la radiación solar, el movimiento del agua en cauces naturales o artificiales, la energía oceánica y el calor de los yacimientos geotérmicos y los bioenergéticos como fuentes renovables para producir energía eléctrica. Por su parte, el artículo 73 constitucional, en su fracción $\mathrm{X}$, otorga la facultad al Congreso de la Unión para legislar en toda la República sobre energía eléctrica, dando el fundamento constitucional a los legisladores para expedir todo tipo de leyes que promuevan la producción de energía eléctrica, incluyéndose en este rubro las energías alternas como fuentes para producir energía eléctrica. Los anteriores preceptos son los que dan fundamento constitucional al Estado para hacer uso y fomentar la creación de bienes y servicios y diversificar las fuentes que producen energía eléctrica. Fundamentan también que los legisladores tienen la atribución de legislar en dicha materia, asumiendo los compromisos internacionales que México haya ratificado ${ }^{16}$. Cabe mencionar que constitucionalmente se hace referencia a las energías renovables; sin embargo, las energías alternas se derivan de forma tácita por su propio fin de brindar energía. De ahí el énfasis de que estas se consideren explícitamente en las leyes mexicanas a fin de darles mayor soporte jurídico y, por ende, mayor auge social. La introducción de la regulación de las energías renovables en el marco jurídico nacional tiene relativamente poco tiempo; se puede considerar que es

\footnotetext{
16 GASCÓN, M., "Regulación de Energías Alternas en México", Revista de Derechos Humanos y Estudios Sociales, núm. 2, 2009, pp. 1-15.
} 
a partir de la promulgación de la Ley para el Aprovechamiento de las Energías Renovables y la Transición Energética (Diario Oficial de la Federación, 28 de noviembre de 2008), y de su respectivo Reglamento de 2009, que se cuenta propiamente con los instrumentos de regulación básicos de una normativa en la materia: "Se podría afirmar que la respuesta a las necesidades energéticas son las Energías Renovables, las cuales por desgracia no se encuentran vinculadas con la cotidianidad de las formas de energía tradicionales, ni tienen amplios instrumentos jurídicos que las regulen, o bien son de incipiente creación"17.

Atendiendo a esta premisa, es necesario analizar las disposiciones jurídicas en México sobre las energías alternas a fin de observar en qué medida se incorpora el $\mathrm{H}_{2}$ como alternativa energética. Para ello, se parte de un análisis de la legislación federal que busca reconocer en todo momento las disposiciones constitucionales y los compromisos internacionales para reducir las emisiones de gases de efecto invernadero (GEI). A consecuencia de lo anterior, el Gobierno federal ha elaborado diversos programas que promueven el uso de energías alternas como el Proyecto de Servicios Integrales de Energía, que tiene como propósito dotar de electricidad a unas 2.500 comunidades rurales; el Proyecto de Energías Renovables a Gran Escala, que busca apoyar a México para desarrollar un proyecto de energía renovable interconectado con base en criterios comerciales de 100 MW; el Programa Transversal de Vivienda Sustentable, que prevé la incorporación de energías renovables y estrategias de uso racional de los recursos para fomentar las viviendas sustentables; y el Programa de Hipoteca Verde, que comprende un crédito que incluye un monto para la compra de una vivienda ecológica18. La legislación19 aplicable a la materia de energías renovables es relativamente nueva dentro del marco jurídico nacional, si bien existen varios ordenamientos de regulación indirecta, es decir, que el contenido de sus disposiciones se involucra con aspectos vinculados con las energías renovables. Existen otras leyes que inciden en el aprovechamiento de la energía a fin de hacer eficientes los procesos, reducir contaminantes y promover políticas públicas en beneficio del aprovechamiento

\footnotetext{
${ }^{17}$ Dirección General de Servicios de Documentación y Análisis de la LXII Legislatura de la Cámara de Diputados, 2014.

18 Subsecretaría de Planeación Energética y Desarrollo Tecnológico, "Programa Especial para el Aprovechamiento de Energías", Diario Oficial de la Federación, 2009.

${ }^{19}$ Ley para el Aprovechamiento Sustentable de la Energía y el Financiamiento de la Transición Energética, Ley de Promoción y Desarrollo de los Bioenergéticos y Ley de la Industria Eléctrica.
} 
energético $^{20}$. Es importante resaltar que esta normativa no hace referencia alguna al hidrógeno $\left(\mathrm{H}_{2}\right)$ como alternativa energética, por lo que, considerando todos los beneficios ambientales, económicos y sociales que se promueven con su uso y aplicación, es pertinente e imperativo que se incorpore en el marco jurídico mexicano a fin de promover la investigación, promoción y aplicación de este elemento como fuente alterna de energía, sobre todo su uso en las celdas de combustible como generadores de energía eléctrica. Con la finalidad de puntualizar el contenido del marco legislativo en México, se analizarán las principales leyes, reglamentos y normas a fin de demostrar la necesidad de incorporar el $\mathrm{H}_{2}$ como alternativa energética.

\section{La Ley para el Aprovechamiento Sustentable de la Energía y el Financiamiento de la Transición Energética (LASEFTE)}

Publicada en el Diario Oficial de la Federación (DOF) el 28 de noviembre de 2008, su contenido de cuatro capítulos, conformado por 31 artículos y sus respectivos transitorios, tiene como objeto principal propiciar un aprovechamiento sustentable de la energía mediante el uso óptimo de esta en todos sus procesos y actividades, desde su explotación hasta su consumo, es decir, reducir la cantidad de energía que usualmente estamos acostumbrados a gastar para satisfacer las necesidades mediante acciones que aseguren una calidad igual o superior de energía y que ayuden a disminuir los impactos ambientales negativos derivados de la generación, distribución y consumo de energía ${ }^{21}$.

\footnotetext{
${ }^{20}$ Ley de la Comisión Regulatoria de Energía; Ley General para la Prevención y Gestión Integral de los Residuos; Ley General de Desarrollo Forestal Sustentable; Ley de Petróleos Mexicanos; Ley de Energía Geotérmica; Ley de Energía para el Campo; Ley del Fondo Mexicano del Petróleo para la Estabilización y el Desarrollo; Ley del Servicio Público de Energía Eléctrica; Ley de Impuestos sobre la Renta (artículo 40, fracción XII); Ley que declara reservas mineras nacionales los yacimientos de uranio, torio y las demás substancias de las cuales se obtengan isótopos hendibles que puedan producir energía nuclear; Ley General del Equilibrio Ecológico y la Protección al Ambiente (evaluación del impacto ambiental); Ley de Aguas Nacionales; Ley Orgánica de la Administración Pública Federal (artículo 33); Reglamento de la Ley para el Aprovechamiento Sustentable de la Energía y el Financiamiento de la Transición Energética; Reglamento de la Ley General del Equilibrio Ecológico y la Protección al Ambiente en materia de impacto ambiental; Reglamento de la Ley de Aguas Nacionales; Norma Mexicana NMX-ES001-NORMEX-2005 de energía solar-rendimiento térmico y funcionalidad de colectores solares para calentamiento de agua, métodos de prueba y etiquetado; Norma Ambiental para el Distrito Federal NADF-008-AMBT-2005, que establece las especificaciones técnicas para el aprovechamiento de la energía solar en el calentamiento de agua en albercas, fosas de clavados, regaderas, lavamanos, usos de cocina, lavandería y tintorería; y Norma Oficial Mexicana PROY-NMX-ES-002-NORMEX-2006.
}

${ }^{21} \mathrm{Se}$ excluye del objeto de la presente Ley la regulación de las fuentes para generar electricidad derivadas de minerales radioactivos para generar energía nuclear; de energía hidráulica con capacidad para generar más de 30 megawatts; de residuos industriales o de cualquier tipo cuando sean 
Esto abrió la posibilidad dentro de estas acciones a la utilización de energías renovables. Cabe mencionar que con la expedición de esta ley se constituyó la Comisión Nacional para el Uso Eficiente de la Energía (CONUEE), que es un órgano administrativo desconcentrado de la Secretaría de Energía que cuenta con autonomía técnica y operativa. La independencia de este órgano busca facilitar las acciones en pro del uso de energías alternas, pues es una comisión técnica y se presume que su personal está capacitado para tomar decisiones informadas enfocadas a promover el uso de dichas energías alternas. El primer capítulo de la LASEFTE refiere a los aspectos generales que indican el objetivo y determinan la forma de la Ley, argumentando que busca regular el aprovechamiento de fuentes de energía renovables y las tecnologías limpias para generar electricidad con fines distintos de la prestación del servicio público de energía eléctrica, así como establecer la estrategia nacional y los instrumentos para el financiamiento de la transición energética. Adicionalmente, en el capítulo se pueden encontrar otros aspectos importantes:

- Se indican cuáles son las fuentes para generar electricidad que se excluyen de ser reguladas por el ordenamiento.

- Se vincula la Ley, en cuanto a su contenido, con la Estrategia Nacional para la Transición Energética.

- Se destaca la inclusión del significado de diversos términos para efectos de mayor entendimiento del ordenamiento, por ejemplo: energías renovables, externalidades, estrategia, generador, programa y suministrador, entre otros.

El capítulo II, referente al papel de la autoridad, indica que el titular del Ejecutivo Federal en materia de energías renovables deberá implementar sus atribuciones a través de la Secretaría de Energía (SENER), para la cual se determinan diversas funciones, entre las que destacan las siguientes:

- Elaborar y coordinar el Programa Especial para el Aprovechamiento de Energías Renovables.

- Coordinar el Consejo Consultivo para las Energías Renovables.

incinerados o reciban algún otro tipo de tratamiento térmico; y del aprovechamiento de rellenos sanitarios que no cumplan con la normativa ambiental. 
- Definir las políticas y medidas para fomentar una mayor integración nacional de equipos y componentes para el aprovechamiento de las energías renovables y su transformación eficiente (en coordinación con la Secretaría de Economía).

- Observar los compromisos internacionales adquiridos por México en la materia.

- Observar lo establecido en los programas nacionales en materia de mitigación del cambio climático.

- Establecer y actualizar el Inventario Nacional de las Energías Renovables.

- Elaborar y publicar el Atlas Nacional de zonas factibles para desarrollar proyectos generadores de energías renovables.

En este apartado también se indican cuáles son las atribuciones de la Comisión Reguladora de Energía en la materia en cuanto órgano encargado de expedir diversos instrumentos regulatorios, entre los que destacan los siguientes: normas, directivas, metodologías y demás disposiciones de carácter administrativo; instrumentos de regulación para el cálculo de las contraprestaciones por los servicios que se presten entre sí los suministradores y los generadores; metodologías para determinar la aportación de capacidad de generación de las tecnologías de energías renovables al Sistema Eléctrico Nacional; reglas generales de interconexión al Sistema Eléctrico Nacional; y procedimientos de intercambio de energía y los sistemas correspondientes de compensaciones. Por último, cabe destacar que en este capítulo se incluyen los aspectos relativos a la participación de los gobiernos del Distrito Federal, de los estados y de los municipios, principalmente en cuanto a la celebración de convenios y acuerdos de coordinación con el Ejecutivo Federal, con el objeto de que, en el ámbito de sus respectivas competencias, se lleven a cabo diversas acciones, entre las que destacan las siguientes:

- Establecimiento de bases de participación para la instrumentación de disposiciones en la materia.

- Promoción de acciones de apoyo al desarrollo industrial para el aprovechamiento de las energías renovables.

- Facilitación del acceso a las zonas con un alto potencial de fuentes de energías renovables para su aprovechamiento y promoción de la compatibilidad de los usos del suelo para tales fines. 
- Establecimiento de regulaciones de uso del suelo y de construcciones que tomen en cuenta los intereses de los propietarios o poseedores de terrenos para el aprovechamiento de las energías renovables.

- Simplificación de los procedimientos administrativos para la obtención de permisos y licencias para los proyectos de aprovechamiento de energías renovables.

En la primera parte del capítulo III se incluyen los preceptos relativos a las normas de elaboración del Programa Especial para el Aprovechamiento de Energías Renovables, así como también se determina que corresponde a la Secretaría de Energía la coordinación de su ejecución mediante la implementación de diversas acciones, entre las que destacan: el establecimiento de objetivos y metas específicos para el aprovechamiento de energías renovables; la determinación de las metas de participación de las energías renovables en la generación de electricidad; la inclusión de proyectos de construcción de las obras de infraestructura eléctrica necesarias para proyectos de energías renovables; y la definición de estrategias para promover la realización de proyectos de generación de electricidad a partir de energías renovables, principalmente. Por otro lado, en este capítulo también se incluyeron las atribuciones de la Comisión Reguladora de Energía en cuanto a diversos aspectos en materia de energías renovables: la determinación de contraprestaciones mínimas y máximas que pagarán los suministradores a los generadores que utilicen energías renovables; la expedición de las directrices a que se sujetarán los modelos de contrato entre los suministradores y los generadores que utilicen energías renovables; y el otorgamiento de permisos para la celebración de contratos de largo plazo entre los suministradores y los generadores que utilizan energías renovables.

La LASEFTE refiere en su capítulo IV la Estrategia Nacional para la Transición Energética y el Aprovechamiento Sustentable de la Energía, que es un mecanismo mediante el cual el Estado mexicano impulsa las políticas, programas, acciones y proyectos encaminados a conseguir una mayor utilización y aprovechamiento de las fuentes de energía renovables y las tecnologías limpias, promoviendo la eficiencia y sustentabilidad energética, así como la reducción de la dependencia de México de los hidrocarburos como fuente primaria de energía (petróleo y gas natural). Dicha Estrategia tiene como objetivo primordial promover la utilización, el desarrollo y la inversión en las energías renovables. Por último, a través de las disposiciones de este capítulo se determinan las normas relativas al Fondo para la Transición Energética y el 
Aprovechamiento Sustentable de la Energía, el cual tiene como fin promover los objetivos de la Estrategia. Al respecto, también se indica que el Ejecutivo Federal diseñará e instrumentará las políticas y medidas oportunas para facilitar el flujo de recursos derivados de los mecanismos internacionales de financiamiento relacionados con la mitigación del cambio climático. Cabe señalar que en esta ley no se incluye el uso específico del hidrógeno como fuente alterna de energía, solamente se consideran las fuentes primarias.

\section{Reglamento de la Ley para el Aprovechamiento de Energías Renovables y el}

\section{Financiamiento de la Transición Energética}

Este ordenamiento fue publicado en el Diario Oficial de la Federación el 2 de septiembre de 2009. Constituido por 45 artículos distribuidos en cuatro títulos, once capítulos y dos secciones, tiene como objeto reglamentar la Ley para el Aprovechamiento de Energías Renovables y el Financiamiento de la Transición Energética. Este ordenamiento contiene diversas normas relativas principalmente a los instrumentos de suministro eléctrico. En el título primero define lo que se entiende por beneficios económicos netos, cogeneración eficiente, consejo, generación renovable, inventario y red eléctrica. Aborda la competencia en la interpretación del Reglamento. Determina los criterios para la utilización de fuentes de energía renovable: el fortalecimiento de la seguridad energética del país; la disminución en la variación de los costos de la energía eléctrica; la reducción en los costos de operación; la participación social; el impulso al desarrollo regional, industrial y tecnológico del país; la reducción de los impactos ambientales y en la salud pública (causados por el uso de combustibles de origen fósil); la reducción de las emisiones de gases de efecto invernadero; y el aprovechamiento de la biomasa.

Asimismo, hace referencia a los convenios y acuerdos de colaboración de la Secretaría con dependencias y entidades de la Administración Pública Federal; a los convenios o acuerdos de coordinación entre la Secretaría de Energía y las autoridades de los gobiernos de las entidades federativas; a los convenios de concertación de la Secretaría para promover la participación de las personas y del sector social involucrados en la formulación y aplicación de medidas para la transición energética; y a la integración y características de los miembros del Consejo Consultivo para las Energías Renovables. En el título segundo se refiere al Inventario Nacional de las Energías Renovables y de la 
Planeación, su contenido e información básica, a la elaboración y evaluación del Programa Especial para el Aprovechamiento de Energías Renovables y a los recursos de la Estrategia Nacional para la Transición Energética y el Aprovechamiento Sustentable de la Energía.

Respecto al título tercero, aborda la integración de tecnologías para la generación renovable en el desarrollo industrial nacional, las acciones del gobierno para la generación renovable, la promoción de la generación renovable vinculada al desarrollo social y rural, y la promoción de la investigación aplicada y del desarrollo de tecnologías para la generación con fuentes de energías renovables. El título cuarto cita la regulación de la generación renovable y de la cogeneración eficiente; las directivas y metodologías para el cálculo de las contraprestaciones y las directrices a que se sujetarán los modelos de contrato para proyectos de pequeña producción $\mathrm{y}$ producción independiente de energía; y los criterios, metodologías y directrices a que se sujetarán los modelos de contrato, procedimientos de intercambio de energía y sus correspondientes sistemas de compensaciones, para proyectos de autoabastecimiento con energías renovables y proyectos de cogeneración eficiente.

Asimismo, refiere las metodologías para determinar la capacidad de generación aportada por las distintas tecnologías al Sistema Eléctrico Nacional; las reglas generales de interconexión al Sistema Eléctrico Nacional; la expedición de las licitaciones; el cálculo de las contraprestaciones por los servicios que se presten entre sí el suministrador y los generadores renovables o cogeneradores eficientes; las licitaciones para proyectos de generación renovable y de cogeneración eficiente; los modelos de contrato y las reglas de procedencia que regirán la adquisición por parte del suministrador de energía eléctrica producida por los generadores renovables y por los cogeneradores; las contraprestaciones por energía y capacidad para los proyectos de generación renovable; y las metodologías para la determinación de las contraprestaciones de los proyectos de cogeneración eficiente y el caso específico de los convenios que se celebren entre el suministrador y Petróleos Mexicanos o sus organismos subsidiarios para proyectos de cogeneración eficiente.

\section{Ley de Promoción y Desarrollo de los Bioenergéticos}

Esta ley fue publicada en el Diario Oficial de la Federación el 1 de febrero de 2008 y 
se integra con 31 artículos distribuidos en cuatro títulos y nueve capítulos. Reglamenta lo previsto en los artículos 25 y 27, fracción XX, de la CPEUM, es de observancia general en toda la República mexicana y tiene por objeto la promoción y el desarrollo de los bioenergéticos con el fin de coadyuvar a la diversificación energética y el desarrollo sustentable como condiciones que permiten garantizar el apoyo al campo mexicano. Asimismo, establece las bases para promover la producción de insumos para bioenergéticos a partir de las actividades agropecuarias y forestales, las algas y los procesos biotecnológicos y enzimáticos del campo mexicano, sin poner en riesgo la seguridad y soberanía alimentaria del país (de conformidad con lo establecido en los artículos 178 y 179 de la Ley de Desarrollo Rural Sustentable). Asimismo, determina las bases para desarrollar la producción, comercialización y uso eficiente de los bioenergéticos para contribuir a la reactivación del sector rural, la generación de empleo y una mejor calidad de vida para la población, en particular la de alta y muy alta marginalidad; para promover, en términos de la Ley de Planeación, el desarrollo regional y el de las comunidades rurales menos favorecidas; para procurar la reducción de emisiones contaminantes a la atmósfera y de gases de efecto invernadero, utilizando para ello los instrumentos internacionales contenidos en los tratados en que México sea parte; y para coordinar acciones entre los gobiernos federal, estatales, del Distrito Federal y municipales, así como la concurrencia con los sectores social y privado, para el desarrollo de los bioenergéticos.

\section{Ley de la Industria Eléctrica}

Publicada en el DOF el 11 de agosto de 2014, es reglamentaria de los artículos 25, párrafo cuarto, 27, párrafo sexto, y 28, párrafo cuarto, de la Constitución Política de los Estados Unidos Mexicanos y tiene por objeto regular la planeación y el control del Sistema Eléctrico Nacional, el Servicio Público de Transmisión y Distribución de Energía Eléctrica y las demás actividades de la industria eléctrica. Las disposiciones de esta ley son de interés social y orden público. Tiene como finalidad promover el desarrollo sustentable de la industria eléctrica y garantizar su operación continua, eficiente y segura en beneficio de los usuarios, así como el cumplimiento de las obligaciones de servicio público y universal, de energías limpias y de reducción de emisiones contaminantes. En particular, esta ley es relevante porque es el único ordenamiento jurídico en México que cita específicamente al hidrógeno $\left(\mathrm{H}_{2}\right)$. Al 
referirse a las energías limpias, las define como aquellas fuentes de energía y procesos de generación de electricidad cuyas emisiones o residuos, cuando los haya, no rebasan los umbrales establecidos en las disposiciones reglamentarias que para tal efecto se expidan. Entre ellas menciona la energía generada por el aprovechamiento del hidrógeno mediante su combustión o su uso en celdas de combustible, siempre y cuando se cumplan la eficiencia mínima que establezca la Comisión Reguladora de Energía (CRE) y los criterios de emisiones establecidos por la Secretaría de Medio Ambiente y Recursos Naturales (SEMARNAT) en su ciclo de vida. Esta ley solo menciona la posibilidad de que el sector industrial tenga autorización de usar el $\mathrm{H}_{2}$, pero no regula su aprovechamiento, lo cual es una de las grandes deficiencias o lagunas del marco jurídico mexicano en materia de energías alternas.

Señala esta ley que la Secretaría de Energía implementará mecanismos que permitan cumplir la política en materia de diversificación de fuentes de energía, seguridad energética y promoción de fuentes de energías limpias. La Secretaría establecerá las obligaciones para adquirir certificados de energías limpias e instrumentará los demás mecanismos que se requieran para dar cumplimiento a la política en la materia, y podrá celebrar convenios que permitan su homologación con los instrumentos correspondientes de otras jurisdicciones ${ }^{22}$. Conviene señalar lo que dispone en particular la Ley del Impuesto sobre la Renta, donde se establece que los contribuyentes del Impuesto sobre la Renta (ISR) que inviertan en maquinaria y equipo para la generación de energía proveniente de fuentes renovables podrán deducir el $100 \%$ de la inversión en un solo ejercicio. Con el objeto de que estas inversiones no se hagan con el único fin de reducir la base gravable del impuesto, se contempla como obligación que la maquinaria y el equipo adquiridos se mantengan en operación durante un período mínimo. Ello es una forma de incentivar el uso de fuentes alternas de energía, haciendo posible la implementación de dispositivos electroquímicos generadores de energía como las celdas de combustible, en particular las de óxidos sólidos (SOFC), bajo el hecho de que se reducen los impactos económicos que pueden representar y se incrementa el beneficio ambiental, social y tecnológico que hace posible colocar a México en el camino del desarrollo sustentable. Desafortunadamente,

\footnotetext{
${ }^{22}$ Ley de la Industria Eléctrica, capítulo III, sobre las obligaciones de energías limpias, artículo 121, 2015. Recuperado en abril de 2015, de http://dof.gob.mx/nota_detalle.php?codigo=5355986\&fecha=11/08/2014.
} 
y a sabiendas de que el petróleo es un recurso finito y cada vez más difícil y costoso de extraer, casi el 90\% de la energía producida en México es a base de hidrocarburos, razón por la cual el legislador debe observar la necesidad de implementar políticas públicas a largo plazo que diversifiquen las fuentes de energía para aminorar la dependencia de los hidrocarburos. Sin embargo, el amplio marco jurídico mexicano en materia energética no considera la inclusión del hidrógeno como fuente alterna de energía, limitando con ello la inserción del país en la era tecnológica actual, que es una realidad en países del Primer Mundo como España, Alemania, Japón o los Estados Unidos.

\section{EL HIDRÓGENO COMO FUENTE ALTERNA DE ENERGÍA}

Las reservas probadas de petróleo son suficientes para satisfacer la demanda prevista durante los próximos 20 años $^{23}$. Las fuentes de energía renovables, que se encuentran distribuidas con mayor o menor abundancia por todo el planeta, tienen como característica intrínseca el hecho de ser temporales y no almacenables ${ }^{24}$. La electricidad que se puede producir a partir de ellas tampoco puede ser almacenada en cantidades apreciables. Por todo ello, es necesario un elemento o vector que permita su acumulación transitoria. El hidrógeno es el elemento más abundante pues supone el $90 \%$ de la masa total del universo. Además, se encuentra homogéneamente distribuido en la Tierra. Tiene propiedades químicas que lo hacen especialmente apto para su uso como combustible, como tener un poder energético por unidad de masa casi tres veces superior a la gasolina ${ }^{25}$, siendo además factible su almacenamiento, transporte y distribución, lo que permitiría su aplicación a cualquier segmento de la demanda. El hidrógeno presentaría así un gran potencial como un vector energético de las energías renovables $^{26}$. Sin embargo, el hidrógeno no se encuentra habitualmente en su forma pura, sino combinado con otros elementos $\mathrm{y}$, además, su densidad energética a temperatura y presión ambiente es bastante baja.

\footnotetext{
${ }^{23}$ RAMSAY, W., International Energy Agency. International Partnership for a Hydrogen Economy, 18 de noviembre de 2003.

${ }^{24}$ LUND, P., LINDGREN, J., MIKKOLA, J. y SALPAKARI, J., "Review of energy system flexibility measures to enable high levels of variable renewable electricity", Renewable and Sustainable Energy Reviews, núm. 45, 2015, pp. 785-807. http://dx.doi.org/10.1016/j.rser.2015.01.057.

${ }^{25}$ Departament of Energy of United States. Recuperado en abril de 2015, de $<$ http://energy.gov/>.

${ }^{26}$ CABEZAS, M., FRAK, A., SANGUINETTI, A., FRANCO, J. y FASOLI, H., "Hydrogen energy vector: Demonstration pilot plant with minimal peripheral equipment", International Journal of Hydrogen Energy, núm. 39, 2014, pp. 18165-18172. http://dx.doi.org/10.1016/j.ijhydene.2014.09.040.
} 
El hidrógeno está actualmente introducido en las agendas políticas de países de todo el mundo. Los Estados Unidos, Japón, la Unión Europea y decenas de otros países como Canadá, China, Corea y Australia han lanzado o reforzado acciones, por medio de desarrollos industriales, inversiones y políticas de Estado, en pro del hidrógeno ${ }^{27}$. La mayor parte de los fabricantes de automóviles están llevando a cabo importantes programas para desarrollar vehículos impulsados por células de combustible, y las compañías petroleras están desarrollando nuevos programas para anticiparse al importante mercado futuro del hidrógeno. Una inquietud que surge cuando hablamos de hidrógeno tiene que ver con la seguridad, en términos de su empleo generalizado, debido a su alto poder explosivo. Sin embargo, el uso del hidrógeno como combustible no es una novedad en el mundo. Viene utilizándose desde hace décadas en la industria. Actualmente se producen y utilizan en torno a 50 millones de toneladas de hidrógeno por año ${ }^{28}$ en destilerías, en industrias de fertilizantes, metalúrgicas, electrónicas y de elaboración de alimentos y en la industria espacial y militar. Sumado a esa amplia experiencia, se está trabajando en la elaboración de normas (ISO/TC 197) orientadas a establecer códigos y estándares de seguridad ${ }^{29}$.

\section{Seguridad del hidrógeno}

La extrema inflamabilidad del hidrógeno conlleva una gran preocupación en su introducción como portador de energía. Sobre todo en su aplicación al transporte. Mucha gente relaciona los riesgos del hidrógeno con el accidente del dirigible Hindenburg, pero un escenario más realista sería el accidente que ocurrió en Estocolmo en 1983. Y los esfuerzos deberían centrarse en que accidentes como ese no volvieran a suceder $^{30}$. El hidrógeno tiene algunas propiedades que lo hacen más peligroso que los combustibles convencionales como la gasolina o el gas natural. El bajo límite de

\footnotetext{
${ }^{27}$ ELMER, T., WORALL, M., WU, SHENYI. y RIFFAT, S., "Fuel cell technology for domestic built environment applications: State of-the-art review”, Renewable and Sustainable Energy Reviews, núm. 42, 2015, pp. 913-931. http://dx.doi.org/10.1016/j.rser.2014.10.080.

28 IFP, Energies nouvelles: innovating for energy, 2015. Recuperado el 25 de marzo de 2015, de www.ifp.fr/IFP/en/files/cinfo/ IFP-Panorama04_11-HydrogeneVA.pdf.

${ }^{29}$ WEINER, S., "Advancing the hydrogen safety knowledge base”, International Journal of Hydrogen Energy, núm. 39, 2014, pp. 20357-20361. http://dx.doi.org/10.1016/j.ijhydene.2014.08.001.

${ }^{30}$ BURGHERR, P. y HIRSCHBERG, S., "Comparative risk assessment of severe accidents in the energy sector, Energy Policy, núm. 74, 2014, pp. S45-S56. http://dx.doi.org/10.1016/j.enpol.2014.01.035.
} 
inflamabilidad del hidrógeno en aire es más alto que en los gases licuados del petróleo o la gasolina, pero su rango de inflamabilidad es muy amplio (4-75\% de hidrógeno en aire). En el rango de concentración de 15-45\%, la energía de ignición del hidrógeno es diez veces menor que la de la gasolina. El quenching gap, que es el orificio más pequeño a través del cual la llama se puede propagar, es considerablemente menor para el hidrógeno que para otros combustibles, lo que significa que las prestaciones de los arrestallamas y del equipamiento similar deben ser mejores ${ }^{31}$.

\section{Riesgos y recomendaciones en las instalaciones de hidrógeno}

Los riesgos asociados con el uso del hidrógeno pueden ser caracterizados como fisiológicos (congelación, enfermedades respiratorias y asfixia), físicos (cambios de fase y fallos de componentes) y químicos (ignición y combustión). Debido a la mínima energía que necesita el hidrógeno gaseoso para incendiarse a temperatura y presión ambiente, la experiencia demuestra que el mayor énfasis debe centrarse en la contención del hidrógeno, en la detección de fugas y en la ventilación de las zonas aledañas ${ }^{32}$. El peligro principal está asociado con cualquier forma de hidrógeno que de manera inadvertida produzca una mezcla inflamable o detonante, seguida de fuego $o$ detonación. La seguridad se mejora si los diseñadores y el personal de operación son conscientes de los riesgos específicos asociados al manejo y uso del hidrógeno. Los principales riesgos asociados al manejo y uso del hidrógeno se han clasificado como: a) fuegos y explosiones, b) fugas, c) dispersión del hidrógeno, d) fallo en los tanques de almacenamiento, e) fallos en los sistemas de apertura y cierre, f) purgado, g) fallos en el sistema de vaporización y h) condensación del aire ${ }^{33}$.

\footnotetext{
${ }^{31}$ KUDRIAKOV, S., STUDER, E. y BIN, C., "Numerical simulation of the laminar hydrogen flame in the presence of a quenching mesh", International Journal of Hydrogen Energy, The Third Annual International Conference on Hydrogen Safety, núm. 36, 2011, pp. 2555-2559. http://dx.doi.org/10.1016/j.ijhydene.2010.03.138.

32 GUPTA, S., BRINSTER, J., STUDER, E. y TKATSCHENKO, I., "Hydrogen related risks within a private garage: Concentration measurements in a realistic full scale experimental facility", International Journal of Hydrogen Energy, núm. 34, 2009, pp. 5902-5911. http://dx.doi.org/10.1016/j.ijhydene.2009.03.026.

${ }^{33}$ ELSHERIF, M., MANAN, Z. y KAMSAH, M., "State-of-the-art of hydrogen management in refinery and industrial process plants", Journal of Natural Gas Science and Engineering, núm. 24, 2015, pp. 346356. http://dx.doi.org/10.1016/j.jngse.2015.03.046.
} 
Por otro lado, el hidrógeno tiene otras propiedades ${ }^{34}$ que también pueden suponer riesgo si no se las tiene en cuenta. Por ejemplo, es un potente agente reductor; es inadecuado para ser utilizado en válvulas, tuberías y juntas; forma mezclas explosivas con muchos gases; y se difunde fácilmente a través de agujeros que son lo suficientemente pequeños.

Además, al contrario que los gases licuados del petróleo y los vapores de la gasolina, el hidrógeno es extremadamente ligero y se eleva rápidamente en el aire. En una atmósfera abierta, esto es generalmente una ventaja, pero puede ser peligroso en edificios que no están diseñados para el hidrógeno. En muchos países, las normas de edificación, por ejemplo, en garajes, exigen aberturas de ventilación cerca del suelo para eliminar los vapores de la gasolina, pero esto no es normalmente una ventilación suficiente para fugas de hidrógeno. El hidrógeno liberado en un edificio se puede concentrar a nivel del techo, y la explosión resultante podría ser muy destructiva ${ }^{35}$. Por otro lado, a pesar de que el hidrógeno no es tóxico, pues está clasificado simplemente como asfixiante y no tiene límite umbral de toxicidad, el personal presente durante las fugas, fuegos o explosiones de los sistemas de hidrógeno puede sufrir daños como la asfixia, que se produce cuando el hidrógeno disminuye el porcentaje de oxígeno por debajo del 19,5\% en volumen. Adicionalmente, la onda de expansión de las explosiones puede causar daños como resultado de las sobrepresiones generadas. El calor por radiación que alcanza y es absorbido por una persona desde una llama de hidrógeno gaseoso-aire es directamente proporcional a una serie de factores entre los que se incluyen el tiempo de exposición, el calor de combustión, el tamaño de la superficie ardiente y las condiciones atmosféricas, sobre todo el vapor de agua. Cabe mencionar que el contacto con el hidrógeno líquido puede causar quemaduras serias o quemaduras por congelamiento, quemaduras criogénicas. Este tipo de quemaduras también se pueden sufrir por contacto

\footnotetext{
${ }^{34}$ SAFFERS, J. y MOLKOV, V., "Hydrogen safety engineering framework and elementary design safety tolos", International Journal of Hydrogen Energy, núm. 39, 2014, pp. 6268-6285. http://dx.doi.org/10.1016/j.ijhydene.2013.06.060.

${ }^{35}$ RIVKIN, C., BLAKE, CH., BURGESS, R., BUTTNER, W. y POST, M., “A national set of hydrogen codes and standards for the United States", International Journal of Hydrogen Energy, núm. 36, 2011, pp. 2736-2741. http://dx.doi.org/10.1016/j.ijhydene.2010.03.096
} 
con la superficie de tanques fríos. Largas exposiciones a fugas de hidrógeno líquido podrían dar lugar a hipotermias si no se toman las precauciones necesarias ${ }^{36}$.

\section{Propiedades del hidrógeno que lo hacen más seguro que otros combustibles}

El hidrógeno necesita una fuente de ignición externa para explotar o incendiarse, a diferencia de explosivos como el acetileno, que no la necesita. Un ejemplo de la seguridad que presenta el hecho de que el hidrógeno no sea explosivo lo encontramos en el accidente del Hindenburg ${ }^{37}$. El hidrógeno no es tóxico. Ni el hidrógeno ni los productos de su combustión son tóxicos o perjudiciales. Según datos industriales, aproximadamente el $80 \%$ de las personas que mueren en los accidentes de aviones comerciales no mueren como consecuencia del golpe, sino por el fuego y el humo tóxico ${ }^{38}$. El hidrógeno tiene una alta difusividad, por lo que desaparece rápidamente si se escapa. El doctor Swain, junto con la Universidad de Miami, realizó un experimento en el que comparaba los efectos en un accidente entre un coche con gasolina y otro con hidrógeno. El coche de hidrógeno resultó mucho menos dañado que el de gasolina, entre otras razones por la difusividad del hidrógeno y el hecho de que este elemento sea más ligero que el aire ${ }^{39}$. El hidrógeno no forma una alfombra de fuego. Ello contrasta con los hidrocarburos convencionales como la gasolina y el diésel. El calor radiante emitido por una llama de hidrógeno es diez veces menor al que emite una llama de hidrocarburos. La combustión del hidrógeno produce principalmente calor y agua. Debido a la ausencia de carbono y la presencia de vapor de agua, que absorbe calor cuando el hidrógeno se quema, la llama de hidrógeno tiene un significativo menor calor de radiación comparado con la llama de un hidrocarburo. Este hecho hace que disminuya el riesgo de incendios secundarios. La energía necesaria para incendiar una mezcla de hidrógeno a bajas concentraciones (inferiores al $10 \%$ ) es mayor que la energía necesaria para incendiar el gas natural o la gasolina en sus respectivos rangos de inflamabilidad. De

\footnotetext{
${ }^{36}$ STANEK, J., GIFT, J., WOODALL, G. y FOUREMAN, G., "Hydrogen sulfide: integrative analysis of acute toxicity data for estimating human health risk", Encyclopedia of Environmental Health, 2011, pp. 124-139. http://dx.doi.org/10.1016/B978-0-444-52272-6.00501-8.

37 THOMAS, C., "A review of hindenburg: exploring the truth", International Journal of Hydrogen Energy, núm. 40, 2015, p. 752. http://dx.doi.org/10.1016/j.ijhydene.2014.10.113.

38 Recuperado en abril de 2015, de www.braunforpresident.us/headlines/policy briefs/pbpdf/HydrodgenFueledAircraft.pdf

39 VILLATORO, F., "La diferencia entre el incendio del motor de un coche de hidrógeno y uno de gasolina”, http://francis.naukas.com/2011/01/05/la-diferencia-entre-el-incendio-del-motor-de-un-cochede-hidrogeno-y-uno-de-gasolina/
} 
modo que, en realidad, es más difícil incendiar hidrógeno si está cerca de su límite inferior de inflamabilidad ${ }^{40}$. El hidrógeno se quema rápidamente si se produce ignición, no detona en una atmósfera abierta, no contamina suelos o agua, no es radiactivo, no es cancerígeno y arde en concentraciones significativamente más bajas que el límite de detonación.

\section{Medidas básicas en la seguridad del hidrógeno}

El mayor énfasis debe centrarse en la contención, detección y ventilación, debido a la mínima energía que necesita el hidrógeno gaseoso para incendiarse a presión atmosférica, alrededor de $0,02 \mathrm{~mJ}$, porque la experiencia muestra que el hidrógeno que se escapa se incendia muy fácilmente. Las pérdidas y las acumulaciones se producen a pesar de los mejores esfuerzos para contener el hidrógeno. El procedimiento seguro es eliminar tolas las fuentes probables de ignición o situarlas lejos de las zonas de posibles escapes del hidrógeno. Algunas de las fuentes de ignición más frecuentes durante un accidente pueden ser: chispas eléctricas, electricidad estática, chispas por fricción, chispas por impacto, objetos calientes $(773-854 \mathrm{~K})$ y llamas ${ }^{41}$. Algunas de las normas básicas útiles para el manejo del hidrógeno con seguridad pueden ser: respetar la distancia donde este almacenado el hidrógeno; emplear materiales no combustibles; diseñar las vías de escape y de acceso en caso de emergencia; evitar la calefacción por medios directos; proveer de suficiente ventilación, en techos principalmente; asegurar la renovación continua del aire; clasificar áreas de riesgo; establecer dispositivos adecuados para trabajar en ambientes explosivos; y prohibir todas las fuentes eléctricas de ignición en áreas clasificadas ${ }^{42}$.

\section{Selección de materiales en la seguridad del hidrógeno}

\footnotetext{
${ }^{40}$ Fact sheet series. Hydrogen Safety. Recuperado en abril de 2015, de www.HydrogenAssociation.org

41 MOLKOV, V., "Hydrogen Safety Engineering: The State-of-the-Art and Future Progress", Comprehensive Renewable Energy, núm. 4, 2012, pp. 97-129. http://dx.doi.org/10.1016/B978-0-08087872-0.00418-2.

${ }^{42}$ LI, Z., PAN, X., SUN, KE., ZHOU, W., GAO, D., LIU, S. y MA, J., "Development of safety standard for mobile hydrogen refueling facilities in China", International Journal of Hydrogen Energy, núm. 39, 2014, pp. 13935-13939. http://dx.doi.org/10.1016/j.ijhydene.2014.02.017
} 
Las nuevas tecnologías aplicadas en las fuentes alternas de energía (celdas de combustible, SOFC) requieren materiales confiables, rentables pero sobre todo altamente seguros. La integridad de los componentes dependerá de la estabilidad de los materiales en presencia de atmósferas de $\mathrm{H}_{2}$. Por lo tanto, la elección de materiales es un punto esencial para el manejo seguro y óptimo del hidrógeno ${ }^{43}$. El daño de materiales metálicos inducido por hidrógeno puede ocurrir a través de diferentes mecanismos, siendo los más relevantes: blistering (abultamientos), fragilización y ataque por hidrógeno. En investigaciones recientes, se han realizado importantes avances en el tipo de material empleado para mejorar la difusión del hidrógeno a través de la conformación óptima de la celda (ánodo, cátodo, electrolito), destacando los materiales de estructura perovskita $\left(\mathrm{ABO}_{3}\right)$ con adiciones de cobre y níquel altamente compatibles con hidrógeno ${ }^{44}$. Otras alternativas pueden ser algunas aleaciones de aluminio y acero.

\section{Almacenamiento del hidrógeno}

Uno de los temas que más preocupan al hablar de la economía del hidrógeno es su almacenamiento. Este es un problema aún sin resolver totalmente. Las tecnologías de almacenamiento del hidrógeno tienen que mejorar significativamente para que el establecimiento de un sistema basado en el hidrógeno sea posible. Se podría hablar de dos tipos fundamentales de almacenamiento, el estacionario y el no estacionario. El primero sería el que se tendría en los puntos de producción, en los puntos de distribución y en los puntos de consumo estacionario. El segundo grupo sería el almacenamiento para la distribución y el almacenamiento para consumo durante el transporte. Este último es el que más preocupa, ya que el almacenamiento del combustible a bordo no debería ocupar un espacio excesivo ni representar un alto porcentaje del peso del vehículo. De hecho, una de las mayores barreras para

\footnotetext{
43 MAHATO, N., BANERJEE, A., GUPTA, A., OMAR, S. y BALANI, K., "Progress in Material Selection for Solid Oxide Fuel Cell Technology: A Review”, Progress in Materials Science, en prensa, manuscrito aceptado. http://dx.doi.org/10.1016/j.pmatsci.2015.01.001.

${ }^{44}$ REYES ROJAS, A., ALVARADO-FlORES, J., ESPARZA PONCE, H., ESNEIDER ALCALA, M., ESPITIA CABRERA, I. y TORRES MOYE E., "Symmetry breaking and electrical conductivity of $\mathrm{La}_{0.7} \mathrm{Sr}_{0.3} \mathrm{Cr}_{0.4} \mathrm{Mn}_{0.6} \mathrm{O}_{3-\alpha}$ perovskite as SOFC anode material", Materials Chemistry and Physics, núm. 126, 2011, pp. 773-779. http://dx.doi.org/10.1016/j.matchemphys.2010.12.045.
} 
generalizar la aplicación de la propulsión basada en el hidrógeno es el desarrollo de un sistema de almacenamiento a bordo que pueda suministrar una cantidad suficiente de hidrógeno con un volumen, peso, costo y seguridad aceptables ${ }^{45}$. La mayoría de los métodos de almacenamiento de hidrógeno establecidos tienen ventajas y desventajas, pero ninguno hasta la fecha es claramente superior al resto. Las elecciones de sistemas de almacenamiento de hidrógeno viables se limitan a: tanques de almacenamiento de hidrógeno comprimido (tecnología con más experiencia), tanques de almacenamiento de hidrógeno líquido criogénico (aplicaciones de transporte de larga duración), hidruros metálicos (menor demanda de volumen y una mayor seguridad en comparación con los dos anteriores), hidruros químicos y nanoestructuras de carbono (gran área superficial, baja densidad y un gran volumen de poros $)^{46}$. El almacenamiento a gran escala presenta menos problemas. Entre las soluciones más competitivas están el uso de grandes cavidades subterráneas ${ }^{47}$ y el almacenamiento en gaseoductos con ligeras variaciones de la presión que puedan absorber las fluctuaciones de suministro y demanda. El factor más importante a mejorar a corto plazo es el desarrollo de mejores sistemas de almacenamiento del hidrógeno. Si se falla en esto, se hará tambalear todo el sistema energético del hidrógeno. Es un factor necesario, pero, obviamente, no suficiente. A largo plazo el hidrógeno se podría convertir en el elemento clave del sistema energético mundial ${ }^{48}$.

\section{LA NECESIDAD DE LEGISLAR EL HIDRÓGENO EN MÉXICO}

Actualmente las energías alternativas en México representan cerca del 25\% (energía

\footnotetext{
${ }^{45}$ DUTTA, S., "A review on production, storage of hydrogen and its utilization as an energy resource", Journal of Industrial and Engineering Chemistry, núm. 20, 2014, pp. 1148-1156. http://dx.doi.org/10.1016/j.jiec.2013.07.037

46 SAKINTUNA, B., LAMARI, F. y HIRSCHER, M., "Metal hydride materials for solid hydrogen storage: A review", International Journal of Hydrogen Energy, núm. 32, 2007, pp. 1121-1140. http://dx.doi.org/10.1016/j.ijhydene.2006.11.022.

${ }^{47}$ BAI, M., SONG, K., SUN, Y., HE, M., LI, Y. y SUN, J., “An overview of hydrogen underground storage technology and prospects in China", Journal of Petroleum Science and Engineering, núm. 124, 2014, pp. 132-136. http://dx.doi.org/10.1016/j.petrol.2014.09.037.

${ }^{48}$ ZHANG, X., HWA, S., HO, H., TAN, S., LI, M., LI, G., LI, J. y FENG, Z., "Towards a smart energy network: The roles of fuel/electrolysis cells and technological perspectives", International Journal of Hydrogen Energy, núm. 40, 2015, pp. 6866-6919. http://dx.doi.org/10.1016/j.ijhydene.2015.03.133.
} 
generada $)^{49}$. Cerca del 90\% del territorio nacional presenta una irradiación solar que al día fluctúa entre 5 y 6 kilowatt-hora $(\mathrm{kWh})$ por metro cuadrado (gran capacidad para la generación de energía eléctrica), lo que representa hasta un $70 \%$ más alto en comparación con los grandes desarrollos de aprovechamiento solar a nivel global ${ }^{50}$. El territorio mexicano forma parte del llamado "cinturón solar", que lo ubica entre los principales países con un alto potencial solar, con lo que podría generar grandes cantidades de energía para autoabastecimiento y exportación ${ }^{51}$. México tiene una importante base para la manufactura de módulos solares fotovoltaicos en América Latina, con una capacidad de producción de $245 \mathrm{MW}$, por encima de Brasil, Chile y Argentina. Actualmente se destinará inversión a proyectos de energías alternativas en México que van desde la construcción de una planta de manufactura de aisladores en Monterrey, Nuevo León, hasta el desarrollo de parques eólicos en La Ventosa, Oaxaca.

Se han presentado propuestas para incentivar el uso de tecnologías limpias; una de estas iniciativas fue abordada durante el panel denominado "Agenda Verde B20: de Cannes a México", donde participantes como Luis Farías, vicepresidente de CEMEX, se pronunciaron por aplicar un "impuesto verde" a aquellas empresas o instituciones contaminantes. A partir de los foros de Green Solutions, que promueve las energías alternativas en México, las empresas NGK, Iberdrola, Acciona, Grupo Bimbo, Peñoles, Safran, Ericsson, Nissan, Odebrecht y Rubenius anunciaron diversos proyectos de inversión en México, todos ellos relacionados con temas medioambientales. La empresa Rubenius dio a conocer que invertirá cuatro mil millones de dólares en México en los próximos siete años para contribuir al desarrollo del banco de energía eléctrica más grande del mundo, que estará ubicado en Mexicali, Baja California. La empresa Rubenius, cuya sede está en Dubai, Emiratos Árabes Unidos, instalará y operará un sistema de almacenamiento y regulación de energía generada con procesos sustentables y para ser entregada a los consumidores finales conforme sea demandada. Esta nueva inversión generará 800 empleos directos. La tecnología empleada es similar a un

\footnotetext{
49 SECRETARÍA DE ENERGÍA, "Energías renovables y desarrollo sustentable”. Recuperado el 16 de febrero de 2015, de http://www.energia.gob.mx/portal/Default.aspx?id=2669. Ultima consulta realizada el 25 de marzo de 2015.

${ }^{50}$ INSTITUTO DE INVESTIGACIONES ELÉCTRICAS. Recuperado el 12 de febrero de 2015, de http://vmwl1.iie.org.mx/sitioIIE/sitio/indice.php.

51 EUROPEAN PHOTOVOLTAIC INDUSTRY ASSOCIATION, "Unlocking the sunbelt potential of photovoltaics". Recuperado el 20 de febrero de 2015, de http://www.epia.org/uploads/tx_epiapublications/Sunbelt_Epia_MARCH2011
} 
regulador de voltaje tipo "No-Break", pero de gran tamaño y con capacidad para cubrir las necesidades de ciudades enteras. Una vez que se concluya la obra, será el mayor banco de energías alternativas en México. De igual manera, el almacenamiento masivo de energía es un factor que permitirá diferir y optimizar los flujos de energía, disminuyendo las emisiones de las empresas proveedoras, que en este caso en particular se ubican en los estados de Baja California y Sonora, del lado mexicano. El estado de Oaxaca es una de las regiones más privilegiadas del mundo en cuanto a potencial eólico (cercano a los $6.000 \mathrm{MW}$ ) debido a su ubicación geográfica y las favorables condiciones climatológicas $^{52}$. En el estado de Baja California se están construyendo varias granjas eólicas, con un potencial de entre 4.000 y $8.000 \mathrm{MW}$ de electricidad que requiere un sistema de almacenaje para contar con disponibilidad permanente y atender con regularidad las necesidades de energía. México es uno de los principales países del mundo en producir energía a partir de fuentes geotérmicas. Con un 8,9\% de participación total, en octubre de 2010 México ocupó la cuarta posición (958 MW), solo precedido por los Estados Unidos (3.093 MW), Filipinas (1.904 MW) e Indonesia (1.197 MW), según datos de la Asociación Mexicana de Geotermia (AMG). Esto muestra el gran potencial de las energías alternativas en México. Por su parte, las empresas Spark Plug Europe (NGK), Peñoles, Iberdrola, Acciona, Safran, Ericsson, Odebrecht, Grupo Bimbo y Nissan anunciaron una serie de inversiones relacionadas con proyectos medioambientales que en conjunto suman 2.250 millones de dólares adicionales. En suma, fueron más de 6.250 millones de dólares el monto de las inversiones y proyectos a partir de 2011 sobre los que diversas empresas mexicanas y extranjeras informaron y que tienen como características la generación y el almacenamiento de energías renovables y el desarrollo de nuevos productos con tecnologías verdes. México está cada vez más fuerte, construyendo su futuro de la mano de la innovación y con el compromiso fuerte y decidido de mitigar el deterioro medioambiental que está dañando al planeta. Este esfuerzo por adquirir un compromiso con la sustentabilidad se ha visto reflejado en diversas leyes e iniciativas que se han estado presentando en los últimos años ${ }^{53}$. Varias de estas legislaciones significan retos

\footnotetext{
52 ELliOTT, D., Atlas de Recursos Eólicos de Oaxaca, Laboratorio Nacional de Energía Renovable, Golden, Colorado, 2004.

${ }^{53}$ Como el Programa Especial de Cambio Climático 2008-2012, la Ley para el Aprovechamiento de Energías Renovables en México, el Financiamiento de la Transición Energética y las hipotecas verdes del Instituto del Fondo Nacional de la Vivienda para los Trabajadores (INFONAVIT), entre otras.
} 
para algunos sectores, como es el caso de la prohibición de focos incandescentes de alto consumo en los próximos años (Proyecto NOM-028-ENER-2010) ${ }^{54}$. Asimismo, para los sectores comerciales y de servicios se establecerán los valores de eficacia mínima (eficiencia energética) que deberán cumplir las lámparas fluorescentes lineales. Otro beneficio que han traído estas legislaciones ha sido el desarrollo de energías de cogeneración, donde se utiliza eficientemente la energía eléctrica generada in situ, pero también la energía térmica residual del proceso de generación para los procesos industriales; tan solo en 2010 se aprobaron 29 permisos de este tipo de energías renovables en México. También se tendrá la capacidad de vender excedentes de energía generada, la posibilidad de crear parques de energías renovables para la distribución de energía. Con todo esto, se espera que para el año 2017 el 10\% de la energía producida en el país sea de fuentes renovables particulares. La utilización de $\mathrm{H}_{2}$ para la producción de energía eléctrica requiere especificaciones que garanticen su seguridad en el manejo y uso. El desarrollo de normas y estándares o la implementación de las que se encuentran vigentes en otros países, así como la certificación en el manejo de materiales y sistemas, representan barreras institucionales para la pronta utilización de este combustible que deberán ser superadas. Por este solo hecho es necesaria, no opcional, la regulación jurídica del $\mathrm{H}_{2}$ como materia para energías alternas, debido a los estándares de tecnología global y a las necesidades sociales que demandan día a día mayor nivel de energía, siendo que a la fecha la principal fuente es a través de los fósiles, los cuales tiene una limitación clara en el futuro. En México existe investigación científica que corrobora la necesidad de incorporar el hidrógeno en el marco jurídico de la energía. En el país se están desarrollando proyectos innovadores que buscan proporcionar alternativas ambientalmente viables, investigaciones que se realizan en instituciones académicas y de investigación mediante recursos propios o a través de proyectos como los del Consejo Nacional de Ciencia y Tecnología (CONACYT). Existe cada vez más interés por realizar investigación en temas asociados al hidrógeno, desde su producción hasta su uso final en dispositivos de celdas de combustible y en ocasiones para combustión de este gas.

Algunas de las instituciones dedicadas a ello son el Instituto Politécnico Nacional

\footnotetext{
54 PROYECTO DE NORMA OFICIAL MEXICANA PROY-NOM-028-ENER-2010, Eficiencia energética de lámparas para uso general. Límites y métodos de prueba. Recuperado el 22 de febrero de 2015, de http://www.dof.gob.mx/nota_detalle.php?codigo=5158461\&fecha=09/09/2010
} 
(IPN), el Centro de Investigación y de Estudios Avanzados (CINVESTAV), el Instituto de Investigaciones Eléctricas (IIE), el Instituto Nacional de Investigaciones Nucleares (ININ), el Instituto Mexicano del Petróleo (IMP) y algunos centros CONACYT como el Centro de Investigación en Materiales Avanzados (CIMAV). A pesar del creciente interés, la infraestructura para tecnologías del hidrógeno en México es muy limitada, al igual que la disponibilidad del recurso humano disponible para ello ${ }^{55}$. En este sentido y de acuerdo a las investigaciones realizadas en tales instituciones y su interés en el desarrollo de la tecnología para el hidrógeno, se desprende la importancia de su regulación y de cómo ello trascendería a las esferas sociales a través de prerrogativas jurídicas que encausarían el proceder social y garantizarían el derecho a un medio ambiente, pero, sobre todo, propiciarían el desarrollo y bienestar social. Por lo tanto, es necesaria una reforma legislativa de la LASEFTE que tenga como finalidad el aprovechamiento sustentable de la energía mediante su uso óptimo a fin de regular su impacto ambiental y social. En este sentido, el $\mathrm{H}_{2}$ constituye una verdadera alternativa que ofrece grandes ventajas energéticas y cuya utilización e implementación es factible a través de las celdas de combustible, en específico la de óxidos sólidos (SOFC). El proceso legislativo de reforma (iniciativa, discusión, aprobación, sanción, publicación y vigencia) requiere incorporar el $\mathrm{H}_{2}$ como alternativa energética a fin de que se consideren las especificaciones de su uso y manejo en la legislación a fin de garantizar que su utilización es ambientalmente adecuada, tecnológicamente viable, económicamente factible y socialmente aceptable.

\section{DISCUSIÓN Y CONCLUSIONES}

1. La Constitución Política de los Estados Unidos Mexicanos carece de preceptos constitucionales específicos en materia de energías alternas; actualmente se parte de la interpretación de los contenidos en diversos artículos constitucionales.

2. El obstáculo político-jurídico que enfrentan las energías alternas en México es la deficiencia de los promotores de las energías alternas; existe un monopolio del Estado en cuanto a la generación de energía eléctrica; existe un vacío legal en torno al

\footnotetext{
55 ESTRADA GASCA, C. A. e ISLAS SAMPERIO, J. (coord.), Energías alternas: propuesta de investigación y desarrollo tecnológico para México, primera edición 2010, Academia Mexicana de Ciencias, pp. 107-120.
} 
aprovechamiento de las energías alternas (no hay leyes que induzcan su aprovechamiento); no existen regulaciones regionales sobre el uso de suelos y el acceso a recursos energéticos; la Ley reglamentaria de electricidad indica que la Comisión Federal de Electricidad debe generar al menor costo, lo que se interpreta que en todas sus compras debe preferir la opción más barata (por kWh); por lo tanto, la Comisión Federal de Electricidad no compra kWh renovables.

3. Existe una burocracia excesiva en el sentido de que hay una regulación excesiva dirigida a potenciar dicho sector que impide el desarrollo del emprendimiento para establecer empresas; las instituciones del sector energético son rígidas frente al desarrollo de nuevas fuentes energéticas como el $\mathrm{H}_{2}$ porque están dominadas por quienes se benefician con el statu quo; el marco institucional para la promoción y aplicación de las energías alternas es muy limitado, ya que se prefiere desarrollar las tecnologías para el aprovechamiento de fuentes tradicionales de energía; hay desconocimiento por parte de las autoridades (Secretaría de Energía y otros) sobre la magnitud y el posible aprovechamiento del $\mathrm{H}_{2}$ como fuente alterna de energía.

4. Los precios de los energéticos no reconocen actualmente los costos ambientales (lo que juega en contra de las energías alternas); algunas fuentes energéticas tradicionales tienen subsidios; los energéticos primarios convencionales tienen precios relativamente bajos; los precios de los energéticos primarios convencionales son volátiles; los costos unitarios del aprovechamiento de las energías alternas todavía no son menores que los de las convencionales; se desconocen los precios de los recursos, lo que incrementa los costos de transacción; prevalecen los intereses de los sistemas centralizados (como sistemas económico-técnicos); no se valoran en México las externalidades ambientales $\mathrm{y}$ de salud de las distintas fuentes energéticas; las energías alternas requieren en general inversiones iniciales mayores; no existen mecanismos comerciales para el financiamiento de proyectos de energías alternas; no existen esquemas financieros competitivos para las energías alternas.

5. Existe poca información detallada y confiable sobre los recursos energéticos alternos del país; los stocks tecnológicos del país en energías alternas son prácticamente nulos; se requieren investigación y desarrollo tecnológico para volverlos positivos.

6. Los recursos humanos capacitados para labores de desarrollo de proyectos, ingeniería y operación son escasos; existe una percepción social de que el petróleo es "inagotable"; el público en general y los tomadores de decisiones en particular desconocen los 
beneficios ambientales de las energías alternas; las energías alternas no pertenecen al marco cultural actual; no se valora en México la cobertura energética de largo plazo.

7. El hidrógeno es el elemento más abundante en el universo y el tercero en la Tierra; sin embargo, no es frecuente encontrarlo en su forma pura, sino combinado con otros elementos formando compuestos más estables. De modo que el hidrógeno no es un recurso, sino que hay que producirlo. De entre sus propiedades destaca, por ejemplo, el hecho de que no es explosivo. Para que el hidrógeno arda son necesarias tres condiciones: que se mezcle con un oxidante, que la mezcla esté dentro de los límites de inflamabilidad y que esté presente una fuente apropiada de ignición. Tanto la mezcla de hidrógeno aire como la de hidrógeno oxígeno tienen unos límites de inflamabilidad muy amplios. El hidrógeno es inagotable. Es decir, se puede producir a partir de energías renovables y agua, y cuando se utiliza se emite vapor de agua y calor. Sus materias primas están muy distribuidas.

8. El desarrollo de un sistema de almacenamiento eficiente del hidrógeno es un tema aún sin resolver y representa una de las principales barreras de la implantación de una energética basada en el hidrógeno. El almacenamiento tiene que resolver problemas en relación con el peso, el volumen, el costo y la seguridad, ya sea que se utilice hidrógeno comprimido, licuado, hidruros metálico-químicos o nanoestructuras de carbono para su almacenamiento.

9. La celda de combustible (Fuel Cell), será la principal receptora del hidrógeno. Las grandes ventajas de las celdas de combustible frente a otros sistemas de producción de energía eléctrica son que no producen emisiones, a excepción del vapor de agua, que son muy silenciosas y que pueden alcanzar eficiencias muy altas, sobre todo si el calor que producen es aprovechado, es decir, si se utilizan en cogeneración. Además, son escalables, es decir, que sus potencias oscilan entre unos pocos vatios hasta centrales de varios megavatios (celdas SOFC), y pueden tener usos estacionarios y móviles. Actualmente, la mayoría de las celdas de combustible son mucho más costosas que el sistema convencional con el que compiten (de 2 a 20 veces más) y este es el principal obstáculo para su expansión.

10. La necesidad de tecnologías energéticas nuevas y sostenibles es un hecho en todos los sectores, pero de forma especialmente urgente en el transporte. Las emisiones de gases de efecto invernadero tienen que ser reducidas drásticamente en los próximos años. Es, por lo tanto, un reto convertir el sistema energético actual en uno libre de 
carbono tanto en su tecnología como en su infraestructura. El hidrógeno podría ser utilizado como una forma de almacenar la energía producida por las fuentes renovables de energía. Un reto importante es también conseguir que la energética del hidrógeno sea rentable económica y energéticamente, tanto en la parte de almacenamiento como en la de producción, distribución y aplicaciones. Se tendría que desarrollar una infraestructura adecuada al hidrógeno. Los prototipos de vehículos con celdas de combustible podrían entrar en el mercado en unos quince a veinte años. Además, tiene que convertirse en una energía lo suficientemente segura como para que pueda ser manejada por usuarios no entrenados. El hidrógeno no es más peligroso que otros combustibles, simplemente es diferente.

\section{REFERENCIAS}

ALVARADO FLORES, J., "Estudio comparativo de las diferentes tecnologías de celdas de combustible", Boletín de la Sociedad Española de Cerámica y Vidrio, núm. 52, 2013, pp. 105-117. http://dx.doi.org/10.3989/cyv.142013.

BAI, M., SONG, K., SUN, Y., HE, M., LI, Y. y SUN, J., “An overview of hydrogen underground storage technology and prospects in China", Journal of Petroleum Science and Engineering, núm. 124, 2014, pp. 132-136. http://dx.doi.org/10.1016/j.petrol.2014.09.037.

BURGHERR, P. y HIRSCHBERG, S., "Comparative risk assessment of severe accidents in the energy sector", Energy Policy, núm. 74, 2014, pp. S45-S56. http://dx.doi.org/10.1016/j.enpol.2014.01.035.

CABEZAS, M., FRAK, A., SANGUINETTI, A., FRANCO, J. y FASOLI, H., "Hydrogen energy vector: Demonstration pilot plant with minimal peripheral equipment", International Journal of Hydrogen Energy, núm. 39, 2014, pp. 1816518172. http://dx.doi.org/10.1016/j.ijhydene.2014.09.040.

DAGOUMAS, A., PAPAGIANNIS, G. y DOKOPOULOS, P., "An economic assessment of the Kyoto Protocol application”, Energy Policy, núm. 34, 2006, pp. 2639. http://dx.doi.org/10.1016/j.enpol.2004.05.012.

DUTTA, S., "A review on production, storage of hydrogen and its utilization as an energy resource", Journal of Industrial and Engineering Chemistry, núm. 20, 2014, pp. 1148-1156. http://dx.doi.org/10.1016/j.jiec.2013.07.037 
ELliOTT, D., Atlas de Recursos Eólicos de Oaxaca, Laboratorio Nacional de Energía Renovable, Golden, Colorado, 2004.

ELMER, T., WORALL, M., WU, SHENYI. y RIFFAT, S., "Fuel cell technology for domestic built environment applications: State of-the-art review", Renewable and Sustainable Energy Reviews, núm. 42, 2015, pp. 913-931. http://dx.doi.org/10.1016/j.rser.2014.10.080.

ELSHERIF, M., MANAN, Z. y KAMSAH, M., "State-of-the-art of hydrogen management in refinery and industrial process plants", Journal of Natural Gas Science and Engineering, núm. 24, 2015, pp. 346-356. http://dx.doi.org/10.1016/j.jngse.2015.03.046.

ESTRADA GASCA, Claudio A. e ISLAS SAMPERIO, Jorge (coord.), Energías alternas: propuesta de investigación y desarrollo tecnológico para México, primera edición 2010, Academia Mexicana de Ciencias, pp. 107-120.

GASCÓN, M., "Regulación de Energías Alternas en México", Revista de Derechos Humanos y Estudios Sociales, núm. 2, 2009, pp. 1-15.

GUPTA, S., BRINSTER, J., STUDER, E. y TKATSCHENKO, I., "Hydrogen related risks within a private garage: Concentration measurements in a realistic full scale experimental facility", International Journal of Hydrogen Energy, núm. 34, 2009, pp. 5902-5911. http://dx.doi.org/10.1016/j.ijhydene.2009.03.026.

JABBOUR, J., FATOUMATA, K., HUNSBERGER, C., SÁNCHEZ RODRÍGUEZ, R., GILRUTH, PETER., PATEL, N., SINGH, A., A. LEVY, M. y SCHWARZER, S., "Internationally agreed environmental goals: A critical evaluation of progress", Environmental Development, núm. 3, 2012, pp. 5-24. http://dx.doi.org/10.1016/j.envdev.2012.05.002.

KUDRIAKOV, S., STUDER, E. y BIN, C., "Numerical simulation of the laminar hydrogen flame in the presence of a quenching mesh", International Journal of Hydrogen Energy, The Third Annual International Conference on Hydrogen Safety, núm. 36, 2011, pp. 2555-2559. http://dx.doi.org/10.1016/j.ijhydene.2010.03.138.

LI, Z., PAN, X., SUN, KE., ZHOU, W., GAO, D., LIU, S. y MA, J., "Development of safety standard for mobile hydrogen refueling facilities in China", International Journal 
of Hydrogen Energy, núm. 39, 2014, pp. 13935-13939. http://dx.doi.org/10.1016/j.ijhydene.2014.02.017.

LUND, P., LINDGREN, J., MIKKOLA, J. y SALPAKARI, J., "Review of energy system flexibility measures to enable high levels of variable renewable electricity", Renewable and Sustainable Energy Reviews, núm. 45, 2015, pp. 785-807. http://dx.doi.org/10.1016/j.rser.2015.01.057.

MAHATO, N., BANERJEE, A., GUPTA, A., OMAR, S. y BALANI, K., "Progress in Material Selection for Solid Oxide Fuel Cell Technology: A Review", Progress in Materials Science, en prensa, manuscrito aceptado. http://dx.doi.org/10.1016/j.pmatsci.2015.01.001.

MOLKOV, V., "Hydrogen Safety Engineering: The State-of-the-Art and Future Progress", Comprehensive Renewable Energy, núm. 4, 2012, pp. 97-129. http://dx.doi.org/10.1016/B978-0-08-087872-0.00418-2.

RAMSAY, C., "International Partnership for a Hydrogen Economy", International Energy Agency, 2003.

REYES ROJAS, A., ALVARADO-FLORES, J., ESPARZA PONCE, H., ESNEIDER ALCALA, M., ESPITIA CABRERA, I. y TORRES MOYE, E., "Symmetry breaking and electrical conductivity of $\mathrm{La}_{0.7} \mathrm{Sr}_{0.3} \mathrm{Cr}_{0.4} \mathrm{Mn}_{0.6} \mathrm{O}_{3-\alpha}$ perovskite as SOFC anode material", Materials Chemistry and Physics, núm. 126, 2011, pp. 773-779. http://dx.doi.org/10.1016/j.matchemphys.2010.12.045.

RIVKIN, C., BLAKE, CH., BURGESS, R., BUTTNER, W. y POST, M., “A national set of hydrogen codes and standards for the United States", International Journal of Hydrogen Energy, núm. 36, 2011, pp. 2736-2741. http://dx.doi.org/10.1016/j.ijhydene.2010.03.096.

SAFFERS, J. y MOLKOV, V., "Hydrogen safety engineering framework and elementary design safety tolos", International Journal of Hydrogen Energy, núm. 39, 2014, pp. 6268-6285. http://dx.doi.org/10.1016/j.ijhydene.2013.06.060.

SAKINTUNA, B., LAMARI, F. y HIRSCHER, M., "Metal hydride materials for solid hydrogen storage: A review”, International Journal of Hydrogen Energy, núm. 32, 2007, pp. 1121-1140. http://dx.doi.org/10.1016/j.ijhydene.2006.11.022. 
SHAIKH, M. y KIRKMAN, G., "Costs of certified emission reductions under the Clean Development Mechanism of the Kyoto Protocol”, Energy Economics, núm. 47, 2015, pp. 129-141. http://dx.doi.org/10.1016/j.eneco.2014.10.020.

STANEK, J., GIFT, J., WOODALL, G. y FOUREMAN, G., "Hydrogen sulfide: integrative analysis of acute toxicity data for estimating human health risk", Encyclopedia of Environmental Health, 2011, pp. 124-139. http://dx.doi.org/10.1016/B978-0-444-52272-6.00501-8.

THOMAS, C., "A review of hindenburg: exploring the truth", International Journal of $\begin{array}{llllll}\text { Hydrogen Energy, } & \text { núm. } & \text { 40, 2015, } & \end{array}$ http://dx.doi.org/10.1016/j.ijhydene.2014.10.113.

VASILEIADOU, E., HEIMERIKS, G. y PETERSEN, A., "Exploring the impact of the IPCC Assessment Reports on science", Environmental Science \& Policy, núm. 14, 2011, pp. 1052-1061. http://dx.doi.org/10.1016/j.envsci.2011.07.002.

VILLATORO, F., "La diferencia entre el incendio del motor de un coche de hidrógeno y uno de gasolina”, http://francis.naukas.com/2011/01/05/la-diferencia-entre-elincendio-del-motor-de-un-coche-de-hidrogeno-y-uno-de-gasolina/

WEINER, S., "Advancing the hydrogen safety knowledge base", International Journal of Hydrogen Energy, núm. 39, 2014, pp. 20357-20361. http://dx.doi.org/10.1016/j.ijhydene.2014.08.001.

ZHANG, X., HWA, S., HO, H., TAN, S., LI, M., LI, G., LI, J. y FENG, Z., “Towards a smart energy network: The roles of fuel/electrolysis cells and technological perspectives", International Journal of Hydrogen Energy, núm. 40, 2015, pp. 68666919. http://dx.doi.org/10.1016/j.ijhydene.2015.03.133. 